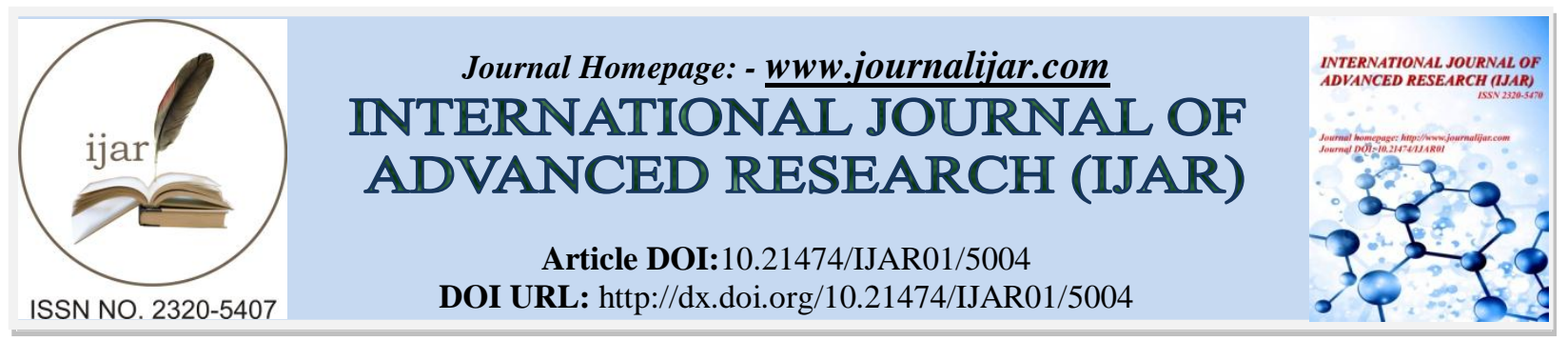

RESEARCH ARTICLE

\title{
SELF PRESENTATION ON FACE BOOK- CONSTRUCTION OF SELF IMPRESSION IN SOCIAL NETWORKING.
}

Dr. Lourdu Vesna. J.

Assistant Professor Mother Teresa Women's University Department of Mass Communication,

\section{Manuscript Info}

Manuscript History

Received: 29 May 2017

Final Accepted: 31 June 2017

Published: July 2017

\section{Abstract}

This study investigates self-presentation strategies among Face book Participants, exploring how participants manage their online presentation of self in order to accomplish the goal of presenting the impression they desire. Thirty-four individuals participated in semistructured interviews about their Face book experiences and perceptions of each other profile and were asked to describe the impression being projected and give a adjective to it. This helped in capturing the impression being "given" and "impression being received" by others. Qualitative data analysis suggests that participants attended to small cues online, mediated the tension between impression management pressures and the desire to present an authentic sense of self through tactics such as creating a profile that reflected their "ideal self," and attempted to establish the veracity of their identity claims. This study provides empirical support for Social Information Processing theory in a naturalistic context.

Copy Right, IJAR, 2017,. All rights reserved.

\section{Introduction:-}

Social Network Sites (SNSs) have become a popular formof social media. On Facebook millions ofusers have created a profile including such data as basicdemographics, personal tastes and, most importantly, a listof "friends" that the subscriber has chosen to associate withpublicly. These profile pages are interesting in that theyallow users to "type themselves into being" and to maketheir social networks visible (boyd\& Ellison, 2007). Much research on SNSs has focused on impression management, exploring the kind of signals generated by a user's profile (Donath, 2007). Observers quickly formstrong impressions (Gosling et al., 2007; Stecher\& Counts, 2008) based on information provided by the owner (e.g. music tastes, Liu, 2007) or more indirect cues (e.g.comments left by friends, Walther et al., 2008). How much and what kind of personal data is revealed can also encourage relationships with others (Lampe et al., 2007).

Profiles tell us how people choose to portray themselves when asked explicitly to do so. However, the more recent phenomenon in which Facebook users post frequent statusupdates offers the opportunity to understand how people manage impressions as a secondary activity when communicating with others. Through the Facebook News Feed, people provide small snapshots of their activities and thoughts via text, sometimes accompanied by photos, web links, or videos. This increased awareness of others' minute actions may have interesting implications for the way we relate to others and understand ourselves. Using a framework inspired by Goffman (1959) we can interpret each of these updates as a "performance," giving the audience (i.e.friends) a chance to form an impression of the updater,

Corresponding Author:-Lourdu Vesna. J.

Address:- Assistant Professor Mother Teresa Women's University Department of Mass 
whether this impression was intentional or not. The Facebook communities are surely aware of the"impression management game" taking place on social networking services and how projected impressions are.

According to the Social PresenceTheory proposed by Short,Williams, and Christie, since Computer Mediated Communication (CMC) users cannot interactdirectly, the lack of nonverbalcues constrains communication.Hence, $\mathrm{CMC}$ users have difficultyin developing interpersonal impressionsand relationships. Contrary to the Social Presence Theory, Waltherproposed the Social Information ProcessingTheory, which posits that CMCcommunication is socially rich inpotential cues used to form interpersonalimpressions and relationships. Consistent with Walther's theory,recent research indicates that CMCinvolves not just verbal cues, but alsononverbal cues that can be manipulatedto develop interpersonal relationships. Recent studies have investigatedthe effects of both nonverbaland verbal cues on social-emotionaldevelopment in CMC.

The study focus on what are attempts made by face bookusers at the core of SNSs profiles that users create to form an image about themselves. Profiles typically involve sharing a photograph of the user and consist of such information as age, location, personal interests and added details in an 'About me' section. This paper wants to outline the core concept "identity" which refers to the way in which users develop their online profiles and list of friends to carry out their online persona.

\section{Objective:-}

What kind of identity signals they send out in to their audience through their profile and to what extent they make it private and public.

What are non verbal cues contribute to the identity formation

What are the main identity traits that are achieved and what non verbal cues influence it more. Is there any gender influence between identity formations?

What are the characteristic of the non verbal cues?

Measuring Impression management:-

"On Face Work" (Goffman, 1963), is an image ofself, delineated in terms of approved social attributes." YetGoffman did not provide a list of tactics people use duringface-work, or a taxonomy of impression formation.Nevertheless, others have attempted to characterize thedimensions of impression management. Examples includethe work of Jones and Pittman (1982), which defines fivetactics used during face-work: ingratiation, intimidation,self-promotion, exemplification (appearing virtuous), andsupplication (looking weak to engender help). McClelland(1988) offered three basic social motivations: power,affiliation, and achievement, and Leary (1995) posited thatpeople are motivated to be seen as physically attractive, likeable, competent, capable, and virtuous. The initial inclination was to adopt one of these taxonomies to characterize face-work on Facebook. Uponinitial examination of the authors' own News Feeds,

however, most of the dimensions did not seem to apply tomost updates. Further, all posts scored high on affiliation because posting an update is in itself an attempt to connect with others. This disparity between posts and existing frameworks for face-work underscored Goffman's insistence on thecontextuality of impression management. To proceed further a set of dimensions that would apply to the type of micro-updates presented on Facebook has obtained from a study "Clandestine chaters: Self-disclosure in U.K. chat room profiles" by Chris Fullwood, Mike Thelwall, Sam O'Niel used the dimensions and they were

1. Cool-Uncool

2. Uplifting - Depressing

3. Self-deprecating - Self-important

4. Appreciative - Critical

5. Entertaining - Boring

Their study do not claim that these dimensions capture the full diversity of face-work on chat room, but they did capture the impressions our subjects believed to be "given" and "given off" in most status updates, so we felt these dimensions are suitable for our study and adapted them in my method to find out which impression trait was dominant and what factors contribute to form that impression. 


\section{Method:-}

34 individuals were selected out of which 15 were female and 19 were male. The notion was added that all theses participants should vary in terms of usage of the Face book (new user, friends lists (more and less), age and gender. A semi structured interview was conducted and each of the thirty four profile, news feeds of the day was distributed and was asked to rate the impression being formed using the dimension and was asked to give reason for their inference. They have to even judge their own profile because this will help the study to find if the impression they wanted to create has been created among others or not.

\section{Data analysis:- \\ Selection of picture to their Profile:-}

Out of the 34, the reason for joining the facebook was almost the same where a majority of 28 among them stated that they joined because their friends already had a profile in it. While asked among the 34 of them 22 of them had their own picture on the profile while 6 of them had film stars of their own choice and 4 had pictures of animal and 2 had pictures of baby. When asked the reason they preferred to claim their identity and not to hide them self.Good looks was the most important aspect when choosing the photo for their SNS profile. Although both genders feel a need to upload a photo that is taken in beautiful surroundings that would commemorate an important event like graduation, wedding, etc. in one`s life or where significant others (friends, family, acquaintances) are accompanying the profile owner on the photo the abovementioned aspects are far more important for the girls than for the male counterparts. Male consider girl profile with pictures of baby as homily and shy and new user to facebook as cool and self important and boring type. Were as female consider male with profile picture of animal to uncool, selfdeprecating type. Thus female participants 12 out of 15 wanted male to revealed their identity in Facebook.

Girls also value highly, photos that reflect their personality (10) the aspect of which is only modestly valued by the boys (9). Nevertheless, bothare slightly more interested in selecting photos that would describe their lifestyle. The analysis of the answers in the interview shows that girls are much more conscious of their selection of photos on the profile. They value both the aesthetic (e.g. beautiful surroundings, photo has a nice look in general), emotional (e.g. important moment, "important others"), self reflectors (e.g. photo reflects my essence, describes my lifestyle), as well as aesthetic-symbolical (good photo-processing, famous photographer) aspects of photographing more than their male counterparts while creating their virtual self. Young men, on the other hand, seem only mildly interested in choosing photos where their handsome looks are portrayed.

\section{No of friends list:-}

Both of the genders equally support the idea that the popularity among one`s peers in SNS can be gained if one has large enough network to begin with. Number of friends one has in one`s friends list is associated to the positive personality of the person on the SNS. Therefore having hundreds of friends is believed to be a highly valuable asset by the young. Theses profile was rated as cool, entertaining, uplifting, and appreciative.

\section{Most influential factor:-}

When asked for the reason for their rating of impression to the profile displayed a grouping of eight non- verbal cues were identified by constant constructive method of grounded theory. The most instant factor that played vital role in impression formation is gender and age and marital status of the profile. Apart from these there are few non verbal cues that play vital role on impression formation on face book. Usage of paralinguistic cues. News feed which has more smileys made the participants consider them to be cool, entertaining, appreciative, uplifting. They are also considered as expressive and extrovert, as emoticons may convey facetiousness on one occasion and sarcasm on another, adding flexibility to otherwise dry communications. But usage of it should be used appropriately too.

Chronemics play a vital role as time taken to respond to the updates or command on the post. The more the time taken is considered to be boring and uncool and self -important.Frequency of messaging, timely response differs in gender in forming the impression. As male consider people who respond frequently as positive personality while female (11) consider them to be negative. Powerful language used in expressing words and attitude, especially computer generated shortcut words. The more they use the more positive image it creates among the participants irrespective of gender.

\section{Post that created response:-}

To which of the post generally they wanted to response was asked without gender difference majority agreed to entertaining. Subjective experience with Facebook suggests these results could reflect two common commenting patterns: the phatic (Schneider, 1998) "ha ha" or "hilarious!" often seenafter an amusing message or offers of 
sympathy like "poor you" or "that's terrible" offered after a participant announces bad news. The "laughs" generated by entertaining updates also illustrate how being funny is one of the "approved social attributes" (Goffman, 1963) that participants want to reinforce through explicit positive feedback in the context of Facebook.

\section{Least influential factor}

The discussion show that for instance, education does not play any role in creating impression in SNS as both genders regard it as the least important influence on identity in social network. Belonging to communities also does not play any role in the identity formation of the person. Although the youth consider belonging to the communities as a forms of self-expression - possibility to "show myself the way I am", to be different, to share wisdom or humor, these types of self-expressions are not recognized as important by the peers. Furthermore, all the other types of creative self-expression that can be performed on the site are also redeemed as second-rate in terms of personality.

\section{Conclusion:-}

While limited in scope, these initial analyses shed some light on the kind of "impression management game"played through Face book status updates. The prevalence ofcool and entertaining updates suggests these dimensions ashighly relevant to successful face-work on SNSs, which isreinforced by their tendency to attract more comments thanother types of posts. While users strive (and often succeed)to project a positive image along these dimensions, theyunderestimate how much certain updates make them lookself-important. This finding is well-aligned with a commonperception that updates can go "too far" and image that clashes with the light-heartedtone of most SNSs. People also believe their posts expressappreciation more than their friends perceive. In a world ofperpetual contact (Joinson, 2008) where people form quickand long-lasting impressions of others (Gosling et al.,2007; Stecher\& Counts, 2008) our data show that users, now more than ever, need to walk a fine line between theimpressions they project on the facebook.

\section{Bibliography:-}

1. boyd, d., \& Ellison, N. B. (2007). Social network sites: Definition, history, and scholarship. Journal of Computer-Mediated Communication, 13(1).

2. Glaser, B. G. (1998). Doing grounded theory: issues and discussions. Mill Valley, CA: Sociology Press.

3. Goffman, E. (1959). The presentation of self in everyday life. Garden City, New York: Doubleday.

4. Goffman, E. (1963). On Face-Work. In Interaction Ritual. New York: Anchor Books.

5. Gosling, S., Gaddis, S., \&Vazire, S. (2007). Personality impressions based on Facebook profiles. In Proceedings of ICWSM 2007.

6. Madanmohan, T. R., \&Navelkar, S. (2002). Roles and knowledge management in online technology communities:an ethnographic study: India Institute of Management,Bagalore (IIMB).

7. McClelland, D. (1988). Human Motivation.Cambridge:Cambridge University Press

8. S. E. Asch, "Forming Impressions of Personality,"Journal of Abnormal and Social Psychology, 41 (1) (1946), 258-290.

9. Y. Liu, The Effects of Nonverbal Cues on Impression Formation in Computer-Mediated Communication: An Exploratory Study, (Commerce, Texas: Texas A\&M University Commerce, doctoral dissertation, 2000). Available from Dissertation Abstracts International, 61 (4), AAT 9965844. 